EGU2020-19575

https://doi.org/10.5194/egusphere-egu2020-19575

EGU General Assembly 2020

(c) Author(s) 2021. This work is distributed under

the Creative Commons Attribution 4.0 License.

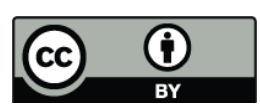

\title{
Modelling water-related processes in rock wall permafrost
}

Florence Magnin, Jean-Yves Josnin, Ludovic Ravanel, and Philip Deline

CNRS, EDYTEM Laboratory, Le Bourget de Lac, France (florence.magnin@univ-smb.fr)

Rock wall permafrost has been increasingly regarded since the early 2000s in reason of the growing frequency and magnitude of bedrock failures from mountain permafrost areas. One of the main current challenges to better assess its degradation and the failure mechanisms is the understanding of hydraulic processes, i.e. water infiltration and circulation in the fractures. Indeed, recent thermal and mechanical models have considered a homogeneous and icesaturated rock medium, overlooking water-related processes which may act along fractures when water percolates. But observations of water stains alongside ice bodies in several rock fall scars point out the need to gain knowledge about such processes.

Recent development in numerical codes allow to fully couple thermal and hydraulic processes, and have so far mostly been used to investigate polar permafrost terrains. In this communication, we will present a first attempt to couple thermal and hydraulic processes in a numerical model of highalpine bedrock permafrost. This entails designing a new modelling approach accounting for heterogeneous (fractured) and non-saturated areas in the rock medium, as well as water outlets and fracture intersections to permit water circulation. We implement Richards equations in the Finite Element simulation system Feflow (DHI-WASY) to model variably saturated flow and advective-conductive heat transports combined with phase change processes. We simulate heat and mass transports in a 2D geometry (vertical cross-section) reflecting the Aiguille du Midi settings (3842 $\mathrm{m}$ a.s.l., Mont Blanc massif, European Alps). The model is forced with climate time series partially constructed out of measured air temperature and assumptions about previous climate period. Steady freezing occurring between 1550 and 1850 AD (Little Ice Age) points out the role of fractures in the freezing rate, as fractures favor infiltration of cold water from the surface, acting as freezing corridors. Under thawing, water movements are enabled in the unfrozen upper parts of the model geometry through a partially saturated domain, whereas the lower part remains saturated. In the thawed zones, fractures that are not completely filled by ice can accelerate water circulation and create thawing corridors.

In this communication, we will present the modelling approach and the preliminary results. We will show that our numerical investigations bear strong potential to address thermal and mechanical effects of water infiltration (from snow melting and rain) and circulation in the frozen bedrock. 